\title{
In silico identification and characterization of novel microsatellite loci for the Blue-and-yellow Macaw Ara ararauna (Linnaeus, 1758) (Psittaciformes, Psittacidae)
}

\author{
Cássia Alves Lima-Rezende ${ }^{1}$, Gislaine Aparecida Fernandes ${ }^{1}$, Helder Elias da Silva ${ }^{1}$, Sarah \\ Dobkowski-Marinho $^{1}$, Victor Fernandes Santos ${ }^{1}$, Fernando Pacheco Rodrigues ${ }^{1}$ and Renato Caparroz ${ }^{1}$ iD \\ ${ }^{1}$ Laboratório de Genética e Biodiversidade, Departamento de Genética e Morfologia, Instituto de Ciências \\ Biológicas, Universidade de Brasília, Campus Universitário Darcy Ribeiro, Asa Norte, Brasilia, DF, Brazil
}

\begin{abstract}
The illegal trade is a major threat to many bird species, and parrots are common victims of this activity. Domestic and international pet markets are interested on different parrot species, such as the Blue-and-yellow Macaw (Ara ararauna). This South American macaw is not globally threatened, but is under protection from over-exploitation. This study aimed to identify and characterize novel microsatellite loci for population and parentage analysis of $A$. ararauna. Scaffold sequences of Ara macao available in the NCBI database were used for microsatellite searches using MsatCommander software. We tested a total of 28 loci, from which 25 were polymorphic, one was monomorphic, and two did not generated amplification products. For polymorphic loci, the mean number of alleles was 8.24 ( $4-15$ alleles per locus), the observed heterozygosity ranged from 0.333 to 0.917 , and the expected heterozygosity from 0.353 to 0.890 . The paternity exclusion probability and identity probability were highly discriminatory. Thus, these novel microsatellite markers can be useful for population assignment and paternity tests, helping the authorities to manage macaws from the illegal trafficking and control commercial breeders.
\end{abstract}

Keywords: Captive breeding, illegal wildlife trade, parentage, Psittacidae, wildlife forensics.

Received: October, 30 2017; Accepted: April 252018.

The illegal trade of plants and animals, as well as their parts and products, is a diverse and profitable business. This business involves billions of dollars, and millions of animals and plants are caught or harvested from the wild and then sold every year around the world (Webb, 2001; Broad et al., 2003). Brazil is one of the major suppliers of the international wildlife trade, and it is estimated that birds represent almost $80 \%$ of the Brazilian market of exotic animals (RENCTAS, 2001; Broad et al., 2003). For instance, the Lear's Macaw (Anodorhynchus leari), Hyacinth Macaw (Anodorhynchus hyacinthinus), Blue-and-yellow Macaw (Ara ararauna), and Red-tailed Amazon (Amazona brasiliensis) are Brazilian parrots commonly sold to illegal pet collectors of Asia, Europe, and North America (RENCTAS, 2001).

Almost half of the 176 parrot species in the Neotropics are threatened to some degree of extinction (Olah et al., 2016). The main threats to Neotropical parrots are the habitat loss due to the expansion of agricultural activities,

Send correspondence to Renato Caparroz. Laboratório de Genética e Biodiversidade, Departamento de Genética e Morfologia, Instituto de Ciências Biológicas, Universidade de Brasília, Campus Universitário Darcy Ribeiro, Asa Norte, 70910-900 Brasilia, DF, Brazil. E-mail: renatocz@yahoo.com.br. hunting and trapping wild animals for the domestic and international pet markets, and logging (Olah et al., 2016; Berkusky et al., 2017). Every year, thousands of parrots are removed from their natural habitat, and the direct and indirect effects of the illegal trade have led to a reduction of some natural populations (Pires, 2012; Berkusky et al., 2017). In general, nestlings illegally removed from their natural habitat are directly sold in fairs and on the margins of Brazilian roads, while others are "laundered" by some legal Brazilian commercial breeders and sold in pet shops as born in captivity.

Although a great number of birds have been confiscated from traffickers and illegal owners, the geographic origin of these animals is frequently unknown, making it very difficult to establish an appropriate wild site where to return these birds (IUCN, 2002). The indiscriminate release of confiscated animals may have negative genetic impacts on local populations, since offspring produced by crosses between individuals from different subpopulations may show signs of reduced fitness (Marshall and Spalton, 2000), known as outbreeding depression. Additionally, the parentage verification is needed to provide evidence of illegal activity of a suspicious commercial breeder (Jan and Fumagalli, 2016). 
In this sense, molecular markers, such as microsatellites, constitute a useful tool for population genetics (Selkoe and Toonen, 2006) and forensic studies (Miller and Bloomer, 2014). In forensics studies of illegal wildlife trade, authorities may use microsatellites in different ways, such as (1) in DNA-based parentage tests to control commercial breeders, avoiding the laundering of wild-caught individuals as captive-bred (Jan and Fumagalli, 2016); and (2) to help in the identification of the probable geographical origin of seized animals by assignment tests (Presti et al., 2015). Although microsatellites have been the preferential markers in forensics studies of non-model species, a relatively limited number of loci is available for parrots (Presti and Wasko, 2014), and only few were isolated for $A$. ararauna (Caparroz et al., 2003).

Here, our goal was to identify and characterize novel polymorphic microsatellite loci for the Blue-and-yellow Macaw (A. ararauna) based on the previously published draft-genome of a congeneric species (Ara macao). The Blue-and-yellow Macaw is a South American species from the Psittacidae family, which is not globally threatened, but is under protection from over-exploitation (CITES II) (Collar et al., 2017). It is estimated that from 1981-1992 approximately 42 thousand individuals of $A$. ararauna were traded internationally (Broad et al., 2003). The set of microsatellite loci described in this study can be useful for population assignment and parentage analysis, helping the authorities to manage victims of illegal trafficking and to control commercial breeders.

The scaffold assembly of Ara macao (Seabury et al., 2013), publicly available under the accession AOUJ00000000.1 in the NCBI database, was used for genome-wide in silico microsatellites searches. Scaffolds were screened for tri-, tetra-, penta-, and hexa-nucleotide microsatellite motifs with 10 or more tandem repeats using the software MSATCOMMANDER 1.0.8 (Faircloth, 2008). The search for locus-specific primers was done using PRIMER3Web (Untergasser et al., 2012) and considering PCR products within a size range between 170 and 350 $\mathrm{bp}$, optimal primers length of $20 \mathrm{bp}$, optimal melting temperature of $58^{\circ} \mathrm{C}\left(56^{\circ} \mathrm{C}-60^{\circ} \mathrm{C}\right), \mathrm{GC}$ content between 40 and $60 \%$, and other parameters set as default. One primer per locus was tagged using an M13 universal sequence (5'-TGT AAA ACG ACG GCC AGT-3') on its 5' end to apply the dye-labeling method proposed by Schuelke (2000). Finally, the online software OLIGO-ANALYZER 3.1 (Integrated DNA Technologies, Coralville, IA) was used to estimate the occurrence of hairpins, self-dimers, and heterodimers among primers.

Total DNA from $24 A$. ararauna blood samples was isolated using proteinase $\mathrm{K}$ digestion followed by phenol-chloroform extraction (Bruford et al., 1992). As the $A$. macao scaffold assembly was used for microsatellite searching, we also extracted the total DNA from one $A$. macao blood sample for use as a positive control in the PCR assays. A ararauna samples were collected in three different localities in Brazil: 14 from Alto Paraíso de Goiás (1403'49.0"S; 47³9'48.4"W), 15 from Parque Nacional das Emas (18 $\left.09^{\prime} 14.4^{\prime \prime} \mathrm{S} ; 52^{\circ} 51^{\prime} 09.4^{\prime \prime} \mathrm{W}\right)$, and five from

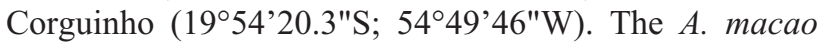
sample was collected from an individual kept in captivity and of unknown origin.

Each locus was initially amplified in eight $A$. ararauna specimens, and the loci that showed success in amplification and polymorphism were used to genotype the other 16 sampled individuals. PCR assays were performed in a $10 \mu \mathrm{L}$ volume containing $20-40 \mathrm{ng}$ of template DNA, 1X PCR buffer, $0.25 \mathrm{mM}$ of each dNTP, $0.08 \mathrm{mM}$ of primer with M13 tail, $0.32 \mathrm{mM}$ of untailed primer, $0.32 \mathrm{mM}$ of fluorescent M13 primer (FAM, HEX, or NED fluorophores, Applied Biosystems, $\mathrm{CA}$ ), $1.5 \mathrm{mM} \mathrm{MgCl}$, and 0.5 unit of Taq polymerase (Invitrogen). Thermocycling conditions were as follows: $94{ }^{\circ} \mathrm{C}$ for $7 \mathrm{~min}$, then 10 cycles at $94{ }^{\circ} \mathrm{C} 1$ $\mathrm{min}$, the locus-specific annealing temperature for $1 \mathrm{~min}$ (see Table 1), $72{ }^{\circ} \mathrm{C}$ for $45 \mathrm{~s}$, followed by 30 cycles at $94{ }^{\circ} \mathrm{C}$ for $1 \mathrm{~min}, 53^{\circ} \mathrm{C}$ for $1 \mathrm{~min}, 72^{\circ} \mathrm{C}$ for $45 \mathrm{~s}$, and a final extension step at $72^{\circ} \mathrm{C}$ for $10 \mathrm{~min}$. Negative (Milli-Q water) and positive (A. macao DNA sample) controls were included in each reaction set. Amplification success was confirmed by electrophoresis on $1 \%$ agarose gel stained with ethidium bromide. A multiplex reaction containing $0.7 \mu \mathrm{L}$ of PCR product of three different loci (each one labeled with a different fluorescent dye) was added to $7.4 \mu \mathrm{L}$ of formamide and $0.5 \mu \mathrm{L}$ of GeneScan 500 ROX size standard (Applied Biosystems), denatured at $95^{\circ} \mathrm{C}$ for $5 \mathrm{~min}$ and separated by capillary electrophoresis in an ABI PRISM 3130 DNA sequencer (Applied Biosystems). Allele sizes were scored in GENEIOUS 6.1.6 software using the Microsatellites Plugin (Biomatters). To confirm the presence of the respective microsatellite locus, one individual (preferably homozygous) for each locus was amplified using the same PCR conditions described above, but using a non-fluorescent M13 primer. We used the Shrimp Alkaline Phosphatase and Exonuclease I protocol to clean the PCR products, and the sequencing was performed by Macrogen (Seoul, Korea).

The number of alleles and observed and expected heterozygosity of each locus were estimated using FSTAT (Goudet, 1995) and IDENTITY 4 (Wagner and Sefc, 1999). The linkage disequilibrium and deviations from Hardy-Weinberg equilibrium (HWE) were tested using GENEPOP 4.3 (Rousset, 2008), and its significance was assessed based on 10,000 permutations with 10,000 batches and 5,000 iterations per batch. For all analysis, $p$-values were adjusted for multiple testing controlling for false discovery rate (Benjamini and Hochberg, 1995). We checked for genotyping errors using MICRO-CHECKER 2.2.3 (Van Oosterhot et al., 2004) with 1,000 Monte Carlo iterations and the Bonferroni confidence interval. Frequencies of null alleles were estimated in MICRO-CHECKER. 
Table 1 - Heterologous primer sequences and characteristics of 28 microsatellite loci for the Blue-and-yellow Macaw (Ara ararauna) drawn from the Ara macao genome. Annealing temperature (Ta) is given in degrees Celsius.

\begin{tabular}{|c|c|c|c|c|}
\hline Locus & NCBI Accession & Primer (5'-3’) & Motif & $\mathrm{Ta}\left({ }^{\circ} \mathrm{C}\right)$ \\
\hline \multirow[t]{2}{*}{ Amac-01 } & AOUJ01027422.1 & F: ACCAACCAAACATGAACAGA & $\operatorname{ATTCT}_{(14)}$ & 54 \\
\hline & & R: CCTTCCTCACGGTTCTTACT & & \\
\hline \multirow[t]{2}{*}{ Amac-02 } & AOUJ01101673.1 & F: CCTTCTTGTTGATCTGCTTG & $\operatorname{GGCAA}_{(13)}$ & 54 \\
\hline & & R: TCTGTCATTAGGAGGCTGAA & & \\
\hline \multirow[t]{2}{*}{ Amac-03 } & AOUJ01106782.1 & F: AGAATGAGTCCCAGGCTTAC & $\mathrm{CCACA}_{(13)}$ & 56 \\
\hline & & R: ACAAGGCAGATAGCACAAGA & & \\
\hline \multirow[t]{2}{*}{ Amac-04 } & AOUJ01379433.1 & F: CCTGAACCAATGTGCTCTAC & $\mathrm{CCAT}_{(30)}$ & 54 \\
\hline & & R: GACAGGGAACTGGGACAGAT & & \\
\hline \multirow[t]{2}{*}{ Amac-05 } & AOUJ01197926.1 & F: TGCAGCTAGTTTGGTCTTGT & $\operatorname{AGGA}_{(24)}$ & 54 \\
\hline & & R: AGTTACCTAAAGCCTGCCTG & & \\
\hline \multirow[t]{2}{*}{ Amac-06 } & AOUJ01268066.1 & F: AGGGACATGCAGGAAAGTAT & $\operatorname{AGAT}_{(15)}$ & 54 \\
\hline & & R: TTAAGTTCCAGGGGGAAGTA & & \\
\hline \multirow[t]{2}{*}{ Amac-07 } & AOUJ01078670.1 & F: GTCCAAATCCATCTGTTTCA & $\operatorname{TCTA}_{(15)}$ & 56 \\
\hline & & R: CCTTTAGCCTCCTCTCACAT & & \\
\hline \multirow[t]{2}{*}{ Amac-08 } & AOUJ01152411.1 & F: CGAGAAGTTTGAAGTTGCAG & $\operatorname{ATCT}_{(15)}$ & 54 \\
\hline & & R: CCAAGCACTATCTTCCCTCT & & \\
\hline \multirow[t]{2}{*}{ Amac-09 } & AOUJ01055174.1 & F: TCAAACCCAAATCACTGTTC & $\operatorname{ATCT}_{(15)}$ & 54 \\
\hline & & R: AAGAAGTGGTGTTCCCTGAT & & \\
\hline \multirow[t]{2}{*}{ Amac-10 } & AOUJ01141428.1 & F: TTTCTTCCTCAAAGGGACAT & $\mathrm{CTAT}_{(15)}$ & 54 \\
\hline & & R: TTTGTATAAGGGCACAGGAA & & \\
\hline \multirow[t]{2}{*}{ Amac-11 } & AOUJ01070479.1 & F: CAGCAGGAGAATTTAAGCAA & $\operatorname{GATG}_{(15)}$ & 54 \\
\hline & & R: CACTTTGTTGGAGGTGGTAA & & \\
\hline \multirow[t]{2}{*}{ Amac-12 } & AOUJ01191554.1 & F: GCAGTGCTCAGAAAGTAAGC & $\mathrm{ATCT}_{(14)}$ & 54 \\
\hline & & R: TTCCTTCCСТCTGATATGGT & & \\
\hline \multirow[t]{2}{*}{ Amac-13 } & AOUJ01191555.1 & F: GCTTCAGTTGGTCATCAAAG & $\operatorname{ATCT}_{(14)}$ & 54 \\
\hline & & R: AGCTGCAAATTAGGGAACTT & & \\
\hline \multirow[t]{2}{*}{ Amac-14 } & AOUJ01209359.1 & F: AAGTTGGAAGAAGACAGGATG & $\operatorname{GGAT}_{(14)}$ & 54 \\
\hline & & R: GCAGCCACATAGAGCAATAA & & \\
\hline \multirow[t]{2}{*}{ Amac-15 } & AOUJ01317281.1 & F: AGCAGGACAGTAAAGGAAGG & $\operatorname{GATG}_{(14)}$ & 56 \\
\hline & & R: AGGAATCAGCTCCAGACTTC & & \\
\hline \multirow[t]{2}{*}{ Amac-16 } & AOUJ01434917.1 & F: CCACAAAGGAAAACTCAATG & $\operatorname{ATCT}_{(14)}$ & 54 \\
\hline & & R: CAGGGCTGTTATGAATGCTA & & \\
\hline \multirow[t]{2}{*}{ Amac-17 } & AOUJ01122363.1 & F: TTAGAGTTGCAGAGCAGGAC & $\operatorname{ATCC}_{(14)}$ & 54 \\
\hline & & R: CAGGTCTCAGAACCCTTCTT & & \\
\hline \multirow[t]{2}{*}{ Amac-18 } & AOUJ01095325.1 & F: GAGCTCAGAGTGTGGACAAC & TGGA $_{(14)}$ & 54 \\
\hline & & R: GCAGTTCAGGCAATTAACAC & & \\
\hline Amac-19 & AOUJ01194686.1 & F: CATCATTTCCСТCTCTTCCT & $\operatorname{ATAG}_{(14)}$ & 54 \\
\hline & & R: ACATGAGTACAGCGTCCATC & & \\
\hline Amac-20 & AOUJ01457062.1 & F: CACCCACCCAACAGTTAAT & $\operatorname{GATA}_{(14)}$ & 56 \\
\hline & & R: TGCCTTTATAGACCCTTTCC & & \\
\hline Amac-21 & AOUJ01152451.1 & F: AGCAAAACCACATTCACATC & $\operatorname{GATG}_{(14)}$ & 54 \\
\hline & & R: AAGTGGAGACCCTGACTGAT & & \\
\hline Amac-22 & AOUJ01126529.1 & F: CTCAGCTGACAGAGAGGAAA & $\mathrm{TCCA}_{(14)}$ & 54 \\
\hline & & R: TCCAACAGAAGGCTTACAAA & & \\
\hline Amac-23 & AOUJ01100929.1 & F: GCACAGAGTGAGAAAGCAAG & $\operatorname{ATCC}_{(13)}$ & 56 \\
\hline & & R: TAGTGTGGGGAACTCAAATG & & \\
\hline Amac-24 & AOUJ01244951.1 & F: GCAGAAGGCAAATAGGTTTT & $\operatorname{GATA}_{(13)}$ & $n a$ \\
\hline & & R: GCAGAAGGCAAATAGGTTTT & & \\
\hline Amac-25 & AOUJ01100098.1 & F: ATTTCCGCTTAGGGTTAATG & $\operatorname{CCAT}_{(13)}$ & 54 \\
\hline & & R: GTGAACATGAGGGAGACAAA & & \\
\hline Amac-26 & AOUJ01052118.1 & F: TAGCTTCGTGCTCTGCTAGT & $\operatorname{TGGA}_{(13)}$ & 54 \\
\hline & & R: TCCTCCTACTTTGCTTCCTT & & \\
\hline Amac-27 & AOUJ01155463.1 & F: CTACTGTTCACCCAGAGCAG & $\mathrm{ACT}_{(17)}$ & 54 \\
\hline & & R: TTGTGCTTTCCTACCTCTTG & & \\
\hline Amac-28 & AOUJ01181657.1 & F: TCATGTGTTCAAAACCTTCC & $\mathrm{GCA}_{(17)}$ & $n a$ \\
\hline & & R: TAAACTCCAGAGCCAATGTG & & \\
\hline
\end{tabular}

na: not amplified 
Paternity exclusion probability and the probability of identity were estimated using IDENTITY.

A total of 1,706 potentially amplifiable microsatellite loci were found: 280 tri-, 999 tetra-, 330 penta-, and 97 hexanucleotides. The most frequent motif was AAAC $(\mathrm{n}=$ $228)$, followed by ATCC $(n=219)$ and AGAT $(n=145)$. In order to obtain a set of microsatellites of different motif lengths, we selected approximately $80 \%$ of tetra-nucleotide motifs and about $10 \%$ of penta- and trinucleotides. For each motif type, the loci with the highest number of repetitions ( $>10$ repetition units) and the most heterogeneous in base composition were selected. Of the 28 tested loci, 26 showed amplification success, but three of them showed non-regularity in the amplifications (Amac-23, Amac-25, and Amac-27), and two did not generate amplification products (Amac-24 and Amac-28; see Tables 1 and 2). Annealing temperatures ranged from 54 to $56^{\circ} \mathrm{C}$ (Table 1), and the se- quencing results indicated homology between the fragments sequenced for A. ararauna and A. macao.

From the 26 loci with amplification success, 25 were polymorphic and only one (Amac-25) was considered monomorphic. However, the latter was one of the loci that showed no regularity in the amplifications, and this state was based on the genotypes of four individuals. The number of alleles per polymorphic locus ranged from four (Amac-21) to 15 (Amac-13), with an average of 8.24 alleles per locus (Table 2). The observed heterozygosity ranged from 0.333 (Amac-14) to 0.917 (Amac-09 and Amac-12) and the expected heterozygosity ranged between 0.353 (Amac-21) and 0.890 (Amac-13; see Table 2). Linkage disequilibrium was not found for any pairwise comparison. Most loci were in HWE, except for five (Amac-02, Amac05, Amac-11, Amac-14, and Amac-16; see Table 2). According to the MICRO-CHECKER results there is signifi-

Table 2 - Genetic diversity of 26 novel microsatellite loci for the Blue-and-yellow Macaw (Ara ararauna). Sample size, number of alleles (NA), size range (Min-Max), observed heterozygosity $\left(\mathrm{H}_{\mathrm{O}}\right)$, expected heterozygosity $\left(\mathrm{H}_{\mathrm{E}}\right)$, frequency of null alleles, probability of exclusion of paternity (PEP), and probability of identity (PI) are given for each locus.

\begin{tabular}{|c|c|c|c|c|c|c|c|c|}
\hline Locus & Sample & NA & Min-Max & $\mathrm{H}_{\mathrm{O}}$ & $\mathrm{H}_{\mathrm{E}}$ & Null & PEP & PI \\
\hline Amac-01 & 24 & 8 & 249-324 & 0.875 & 0.754 & $n s$ & 0.536 & 0.098 \\
\hline Amac-02 & 21 & 8 & $298-396$ & $0.476^{*}$ & 0.833 & 0.1948 & 0.668 & 0.049 \\
\hline Amac-03 & 23 & 11 & 294-349 & 0.870 & 0.858 & $n s$ & 0.715 & 0.036 \\
\hline Amac-04 & 24 & 13 & $266-422$ & 0.750 & 0.766 & $n s$ & 0.561 & 0.088 \\
\hline Amac-05 & 23 & 13 & $300-448$ & $0.826^{*}$ & 0.859 & $n s$ & 0.735 & 0.031 \\
\hline Amac-06 & 22 & 6 & $231-251$ & 0.818 & 0.777 & $n s$ & 0.564 & 0.085 \\
\hline Amac-07 & 22 & 7 & $347-371$ & 0.818 & 0.771 & $n s$ & 0.566 & 0.085 \\
\hline Amac-08 & 23 & 9 & $336-376$ & 0.826 & 0.850 & $n s$ & 0.703 & 0.039 \\
\hline Amac-09 & 24 & 14 & $365-417$ & 0.917 & 0.887 & $n s$ & 0.774 & 0.023 \\
\hline Amac-10 & 24 & 10 & $274-330$ & 0.792 & 0.720 & $n s$ & 0.527 & 0.104 \\
\hline Amac-11 & 24 & 7 & 293-329 & $0.583 *$ & 0.779 & 0.1098 & 0.582 & 0.079 \\
\hline Amac-12 & 24 & 8 & $291-327$ & 0.917 & 0.840 & $n s$ & 0.679 & 0.046 \\
\hline Amac-13 & 23 & 15 & $363-415$ & 0.826 & 0.890 & $n s$ & 0.779 & 0.022 \\
\hline Amac-14 & 22 & 11 & $350-402$ & $0.333^{*}$ & 0.833 & 0.2727 & 0.675 & 0.047 \\
\hline Amac-15 & 22 & 7 & $297-321$ & 0.818 & 0.743 & $n s$ & 0.540 & 0.096 \\
\hline Amac-16 & 21 & 6 & $337-357$ & $0.381 *$ & 0.638 & 0.1571 & 0.415 & 0.170 \\
\hline Amac-17 & 24 & 6 & $223-243$ & 0.833 & 0.720 & $n s$ & 0.508 & 0.112 \\
\hline Amac-18 & 23 & 6 & $182-202$ & 0.783 & 0.696 & $n s$ & 0.457 & 0.141 \\
\hline Amac-19 & 24 & 6 & $213-233$ & 0.833 & 0.766 & $n s$ & 0.546 & 0.093 \\
\hline Amac-20 & 24 & 6 & 298-318 & 0.667 & 0.745 & $n s$ & 0.523 & 0.105 \\
\hline Amac-21 & 24 & 4 & $380-416$ & 0.417 & 0.353 & $n s$ & 0.189 & 0.443 \\
\hline Amac-22 & 23 & 6 & $331-355$ & 0.826 & 0.774 & $n s$ & 0.561 & 0.086 \\
\hline Amac-23 & 4 & 5 & $385-413$ & 0.750 & 0.688 & $n s$ & 0.470 & 0.132 \\
\hline Amac-25 & 4 & 1 & 297 & & & & & \\
\hline Amac-26 & 24 & 9 & $206-254$ & 0.667 & 0.811 & $n s$ & 0.646 & 0.055 \\
\hline Amac-27 & 8 & 5 & $337-358$ & 0.875 & 0.758 & $n s$ & 0.529 & 0.100 \\
\hline Total & & & & & & & $>0.999$ & $6.4 \mathrm{e}-21$ \\
\hline
\end{tabular}

*Departure from Hardy-Weinberg Equilibrium after false discovery rate correction; scoring error due to stuttering; $n s$ : not significant; Loci names in bold indicate the set used to estimate the total PEP and PI. 
cant evidence for a null allele at Amac-02, Amac-11, Amac-14, and Amac-16 loci, and evidence for stutter peaks at locus Amac-16. Based on the set of 18 polymorphic loci with high amplification success and under HWE (see Table $2)$, we found high paternity exclusion probability $(>0.999)$ and low probability of identity $\left(6.40 \mathrm{e}^{-021}\right)$.

Six dinucleotide microsatellites loci previously isolated for $A$. ararauna and genotyped for 49 individuals showed number of alleles varying from one to 11 per locus (Caparroz et al., 2003), being less polymorphic than the set presented here. Additionally, those loci were composed by dinucleotide motifs, which are sometimes difficult to score due to the presence of stutter bands. In addition to being composed by tri-, tetra-, and pentanucleotides, the loci presented here also showed high level of polymorphism, indicating that this set will be useful in the analysis of genetic diversity and population structure of $A$. ararauna and potentially other macaw species. The high paternity exclusion probability and low probability of identity indicate the potential for the use of these loci in parentage analyses of $A$. ararauna, helping authorities to check and control commercial breeders. Moreover, these new microsatellites will help studies about the social structure and mating system of this and other related species.

\section{Acknowledgments}

We are thankful to Cristina Y. Miyaki for providing the blood samples used in this study. This study is part of the Ciências Pró-Forenses - Desenvolvimento e Aperfeiçoamento de metodologias baseadas em marcadores moleculares e isótopos estáveis aplicáveis no combate aos crimes contra a fauna brasileira project (23038.006832/2014-11), supported by the Coordenação de Aperfeiçoamento de Pessoal de Nível Superior (CAPES) and Ministério da Educação (MEC) agencies. VFS received scholarship from Conselho Nacional de Desenvolvimento Científico e Tecnológico (CNPq). GAF and HES received doctoral scholarship from CAPES. CAL-R received a postdoctoral fellowship from CAPES.

\section{Conflict of Interest}

The authors declare that there is no conflict of interest that could be perceived as prejudicial to the impartiality of the reported research.

\section{Author contributions}

All authors planned and designed the research. C.A.L.R, V.F.S. and R.C. carried out the sampling, the laboratory work and performed the molecular analysis. C.A.L.R. and R.C. wrote the manuscript with the help of the other authors.

\section{References}

Benjamini Y and Hochberg Y (1995) Controlling the false discovery rate: A practical and powerful approach to multiple testing. J R Stat Soc Series B Stat Methodol 57:289-300.

Berkusky I, Quillfeldt P, Brightsmith DJ, Abbud MC, Aguilar JMRE, Alemán-Zelaya U, Aramburú RM, Arce Arias A, Balas McNab R, Balsby TJS et al. (2017) Current treats faced by Neotropical parrot populations. Biol Conserv 214:278-287.

Broad S, Mulliken T and Roe D (2003) The nature and extent of legal and illegal trade in wildlife. In: Oldfield S (ed) The trade in wildlife: regulation for conservation. Earthscan Publications, London, pp 3-20.

Bruford MW, Hanotte O, Brookfield JFY and Burke T (1992) Single-locus and multilocus DNA fingerprinting. In: Hoelzel AR (ed) Molecular genetic analysis of populations. IRL Press, Oxford, pp 225-269.

Caparroz R, Miyaki CY and Baker AJ (2003) Characterization of microsatellite loci in the Blue-and-gold Macaw, Ara ararauna (Psittaciformes: Aves). Mol Ecol Notes 3:441443.

Faircloth BC (2008) MSATCOMMANDER: Detection of microsatellite repeat arrays and automated, locus-specific primer design. Mol Ecol Resour 8:92-94.

Goudet J (1995) FSTAT (Version 1.2): A computer program to calculate F-statistics. J Hered 86:485-486.

Jan C and Fumagalli L (2016) Polymorphic DNA microsatellite markers for forensic individual identification and parentage analyses of seven threatened species of parrots (family Psittacidae). PeerJ 4:e2416.

Marshall TC and Spalton JA (2000) Simultaneous inbreeding and outbreeding depression in reintroduced Arabian oryx. Anim Conserv 3:241-248.

Miller SM and Bloomer P (2014) Evaluation of microsatellite markers for populations studies and forensic identification of African Lions (Panthera leo). J Hered 105:1-11.

Olah G, Butchart SHM, Symes A, Guzmán IM, Cunningham R, Brightsmith DJ and Heinsohn R (2016) Ecological and socio-economic factors affecting extinction risk in parrots. Biodivers Conserv 25:205-223

Pires SF (2012) The illegal parrot trade: a literature review. Global Crime 13:176-190.

Presti FT and Wasko AP (2014) A review of microsatellite markers and their application on genetic diversity studies in parrots. Open J Genet 4:69-77.

Presti FT, Guedes NMR, Antas PTZ and Miyaki CY (2015) Population genetic structure in Hyacinth Macaws (Anodorhynchus hyacinthinus) and identification of the probable origin of confiscated individuals. J Hered 106:491-502.

Rousset F (2008) GENEPOP'007: A complete re-implementation of the GENEPOP software for Windows and Linux. Mol Ecol Resour 8:103-106.

Schuelke M (2000) An economic method for the fluorescent labeling of PCR fragments. Nat Biotechnol 18:233-234.

Seabury CM, Dowd SE, Seabury PM, Raudsepp T, Brightsmith DJ, Liboriussen P, Halley Y, Fisher CA, Owens E, Viswanathan $\mathrm{G}$ et al. (2013) A multi-platform draft de novo genome assembly and comparative analysis for the Scarlet Macaw (Ara macao). PLoS One 8:e62415. 
Selkoe KA and Toonen RJ (2006) Microsatellites for ecologists: A practical guide to using and evaluating microsatellite markers. Ecol Lett 9:615-629.

Untergasser A, Cutcutache I, Koressaar T, Ye J, Faircloth BC, Remm M and Rozen SG (2012) Primer3 - new capabilities and interfaces. Nucleic Acids Res 40:1-12.

Van Oosterhout C, Hutchinson WF, Wills DPM and Shipley P (2004) Micro-Checker: Software for identifying and correcting genotyping errors in microsatellite data. Mol Ecol Notes 4:535-538.

Wagner HW and Sefc KM (1999) IDENTITY 1.0. Centre for Applied Genetics, Vienna.

Webb JT (2001) Prosecuting wildlife traffickers: Important cases, many tools, good results. Vermont J Environ Law 2:1-12.

\section{Internet Resources}

Collar N, Boesman P and Sharpe CJ (2017) Blue-andyellow Macaw (Ara ararauna). Handbook of the Birds World Alive,http://www.hbw.com/node/54616 (accessed 13 June 2017).

IUCN (2002) IUCN guidelines for the placement of confiscated animals, https://portals.iucn.org/library/sites/library/files/documents/2002-004.pdf (accessed 10 June 2017).

RENCTAS (2001) $1^{\circ}$ Relatório Nacional sobre o Tráfico de Fauna Silvestre, http://www.renctas.org.br/wp-content/uploads/2014/02/R EL_RENCTAS_pt_final.pdf (accessed 10 June 2017).

Associate Editor: Antonio Matteo Solé-Cava

License information: This is an open-access article distributed under the terms of the Creative Commons Attribution License (type CC-BY), which permits unrestricted use, distribution and reproduction in any medium, provided the original article is properly cited. 